Abstracta Iranica Abstracta Iranica

Revue bibliographique pour le domaine irano-aryen

Volume 26 | 2005

Comptes rendus des publications de 2003

Tombeaux de paradis. Le Shâh-e Zende de Samarcande et la céramique architecturale d'Asie centrale. Ed. d'art Monelle Hayot, 2003, 264 p.

Monik Kervran

(2) OpenEdition

Journals

Édition électronique

URL : http://journals.openedition.org/abstractairanica/2536

ISSN : 1961-960X

Éditeur :

CNRS (UMR 7528 Mondes iraniens et indiens), Éditions de l'IFRI

Édition imprimée

Date de publication : 15 mai 2005

ISSN : 0240-8910

Référence électronique

Monik Kervran, «Tombeaux de paradis. Le Shâh-e Zende de Samarcande et la céramique architecturale d'Asie centrale. Ed. d'art Monelle Hayot, 2003, 264 p. », Abstracta Iranica [En ligne], Volume 26 | 2005, document 289, mis en ligne le 07 décembre 2005, consulté le 25 septembre 2020. URL : http:// journals.openedition.org/abstractairanica/2536

Ce document a été généré automatiquement le 25 septembre 2020.

Tous droits réservés 


\title{
Tombeaux de paradis. Le Shâh-e Zende de Samarcande et la céramique architecturale d'Asie centrale. Ed. d'art Monelle Hayot, 2003, 264 p.
}

\author{
Monik Kervran
}

1 Cet ouvrage se distingue des nombreux volumes consacrés ces dernières années aux monuments islamiques d'Asie centrale en ce qu'il éclaire le lecteur sur les techniques de fabrication des décors qui constituent sans doute l'essentiel de la beauté de ces monuments: leur revêtement glaçuré ou émaillé. Les auteurs se sont attachés à montrer le rôle des artisans qui ont découvert, expérimenté et amélioré les tonalités, la résistance et l'assemblage des éléments de ces décors. Quant aux souverains de l'époque, les Mongols puis les Timourides, malgré les pires brutalités pour détruire les œuvres de leurs prédécesseurs, ils permirent aux découvertes artistiques, notamment en matière de techniques céramiques, de se répandre d'une extrémité à l'autre de leur empire, des confins de la Chine au Levant (p. 203).

2 L'ouvrage se compose de deux parties. La première est un catalogue des monuments d'Asie centrale à décor émaillés pré-timourides et timourides (pp. 30-148). Y sont finement analysés les revêtements décoratifs de ces monuments, mais aussi le contexte historique dans lequel ils ont été édifiés. Une place particulière est faite à la nécropole du Shâh-e Zende (« le roi vivant »), chef d'œuvre incontestable de l'art islamique d'Asie centrale.

3 La deuxième partie, intitulée "La céramique de revêtement en Asie centrale " (pp. 150-251) est sans doute la première approche à la fois globale et technologique de l'évolution du décor architectural d'Asie centrale entre le $12^{\mathrm{e}}$ et le $15^{\mathrm{e}} \mathrm{s}$. J.S. et Y.P. en ont ainsi restitué les étapes. A l'orient du monde islamique, après des siècles d'éclipse, les revêtements architecturaux à glaçure polychrome réapparurent, discrets d'abord et monochromes (oxyde de cuivre seulement). Traditionnellement considéré comme le premier monument (conservé) où s'appliqua cette technique, le Gunbadh al-sorkh 
(Maragha, Azerbaïdjan iranien, 542/1147) a quelques motifs turquoises ponctuant le décor de briques de ses façades ainsi que les caractères de l'inscription dominant son entrée. Dans l'Asie centrale pré-timouride, ce sont aussi les inscriptions - point crucial des monuments islamiques - qui sont revêtues de glaçure bleu turquoise (Magak-i 'attâri de Boukhara, Cheshme-ye 'Ayyub et minaret de Vabkent, mausolées de Kohna Urgench, $12^{\mathrm{e}}-13^{\mathrm{e}}$ siècles). Dans ces monuments, et à la différence des prototypes iraniens où les lettres étaient faites de bâtonnets de briques glaçurés posés à mesure, dans un bandeau réservé à cet effet, les portions d'inscriptions sont préalablement sculptées sur des carreaux d'argile à fond plat (mausolée de Tekesh à Kohna Urgench) ou ornés de rinceaux végétaux en relief (Magak-i 'attâri, Cheshme-ye 'Ayyub), les carreaux étant ensuite posés côte à côte pour former l'inscription.

4 Au siècle suivant se répandirent en Asie centrale de nouvelles techniques visant à introduire d'autres couleurs dans les décors glaçurés. Ces techniques avaient été mises au point, dans la deuxième moitié du $12^{\mathrm{e}} \mathrm{s}$., soit dans les ateliers syro-égyptiens, soit dans ceux de l'Iran du nord (Rayy, Kashan, Gorgan), d'abord pour l'ornementation des pièces de forme. Elles se développèrent en deux étapes. C'est d'abord « un décor peint de pigments noirs qui apparaît en très léger relief... sur un fond d'engobe siliceux blanc couvrant la pâte", le tout recouvert "d'une glaçure alcaline transparente mais additionnée d'oxyde de cuivre ». L'intérêt est d'obtenir, à une température relativement basse $\left(950^{\circ}\right)$ «l'illusion d'un fond turquoise » sur lequel s'enlèvent des motifs d'un noir profond. La Turquie seljuqide a conservé les plus beaux carreaux de ce type à Aspendos et Kubâddâbâd (vers 1235-36). La deuxième étape de cette révolution technologique fut de peindre des décors polychromes sous une glaçure transparente incolore alcalino-plombeuse. Seule une maitrise parfaite de la cuisson, avoisinant les $1100^{\circ}$, et un savant dosage des fondants assurait des glaçures colorées stables et qui ne fusaient pas. Aux bleus turquoise, cobalt et noir/ aubergine toujours présents s'ajoutèrent le blanc, le jaune, le vert, le rouge brun, le rouge plus rarement, ainsi que les effets lustrés puis des techniques où les couleurs étaient séparées par les procédés de type «cuenca y arista» ou "cuerda seca». Les supports devenaient aussi les plus divers: mosaïque, plaques d'argile de toutes dimensions, éléments convexes ou concaves, bandeaux ou carreaux sculptés.

Il n'est évidemment possible de reconstituer l'évolution et le cheminement de ces techniques décoratives qu'à partir des monuments qui nous sont parvenus. Les plus anciens se trouvent au Khwarezm (région traditionnellement en relation avec l'Iran du nord mais aussi la Turquie à travers la Caspienne) : ce sont les mausolées de Seyyed 'Alâ al-Din à Khiva (vers 1305) et de Najm al-Din Kobrâ à Konha Urgench (vers 1330). Au milieu de ce siècle, les céramistes travaillant en Asie centrale sont en pleine possession de leur art et créent des chefs d'œuvre, de la mer d'Aral à la Chine : à Boukhara, le mausolée de Buyân Quli Khân, (c. 1358), à Almaliq, le mausolée de Tugluq Timour, (c. 1363), à Konha Urgench, le mausolée de Tughabeg Khânum, (c. 1370). Du même siècle datent les plus anciens tombeaux et mausolées du Shâh-e Zende à Boukhara, dont on retiendra, parmi les plus beaux, le cénotaphe de Quthâm ibn 'Abbas ( $14^{\mathrm{e}} \mathrm{s}$.), le mausolée de Shâh-e Molk Âqâ (après 1371), celui dit de l'Ostâd 'Ali Nasafi (c. 1380), enfin quelques fragments de l'anonyme $n^{\circ} 2$ (c. 1385), aux merveilleuses étoiles ornées de fleurettes rouges et rehaussées de feuilles d'or de type « lâjvardina ». La variété et la beauté des décors réalisés dans cette nécropole ne se retrouveront plus jamais, ni en Asie centrale ni en Iran. 
6 La construction du livre souffre sans doute de la disparition prématurée de Jean Soustiel. Il en résulte une séparation trop marquée entre les deux parties: «Les Monuments » et «Les Techniques », qui rend difficile à saisir, dans la partie consacrée aux premiers, la manifestation des secondes. La deuxième partie, à elle seule un manuel de céramologie très touffu, aurait demandé à être élaguée. Enfin l'absence de références aux photographies des monuments, en particulier dans la deuxième partie, ajoute à l'effort que doit fournir le lecteur s'il veut pleinement profiter des riches informations contenues dans l'ouvrage.

INDEX

Thèmes : 5.3. Asie centrale

\section{AUTEURS}

MONIK KERVRAN

CNRS - Paris 